\title{
In Situ Characterization of Small-Particle Plasma Sprayed Powders
}

\author{
Y.J. Su, T.F. Bernecki, and K.T. Faber
}

(Submitted 5 October 2000; in revised form 21 December 2000)

\begin{abstract}
The effect of various small-particle plasma spray powder injection parameters on the in situ particle position, velocity, and temperature is measured for yttria-stabilized zirconia and yttrium-aluminum-garnet powder. Using full-factorial experiments and multiple regression analysis, carrier gas flow, injector angle, and powder feeder disc speed were found to significantly affect the particle properties. Temperature and velocity were inversely related; on average, the cooler particles traveled faster. These properties also correlated to the particle position in the flame, where particles above the centerline of the flame traveled faster. The trends are discussed on the basis of residence time in the flame, as well as in terms of particle size segregation effects. Coating density and splat geometry reflect the temperature and velocity differences between the runs. Slower, hotter particles possessed more intrasplat and intersplat porosity and less splat-substrate contact area, leading to lower overall coating density.
\end{abstract}

Keywords in-flight, particle, temperature, velocity

\section{Introduction}

Plasma spraying is used to fabricate metallic and ceramic coatings for wear resistance, corrosion resistance, and thermal barrier applications. In this process, powder is injected into a high-velocity, high-temperature plasma flame and propelled toward a substrate. The feedstock powder can be injected internally ${ }^{[1,2]}$ (inside the nozzle exit) or externally ${ }^{[3-5]}$ (outside the nozzle exit). Regardless of the injection manner, the molten or semimolten particles spread on the substrate surface are rapidly quenched, and form "splats" on impact. A coating is formed by the build-up of individual pancake-like splats (lamellae) as the gun rasters across the surface.

Small-particle plasma spray (SPPS) ${ }^{[6]}$ is a modified air plasma spray system that incorporates a powder injector with a narrower channel and a beveled tip. SPPS was developed to increase coating quality, in particular density, through the use of smaller particles with diameters less than $10 \mu \mathrm{m}$. Theoretically, monosized particles entrained within a carrier gas will minimally perturb the plasma if the width of the carrier jet is infinitesimally thin. In order to implement this concept, the SPPS injector has an elliptical orifice with the minor diameter determined by the size of the particle to be sprayed. Furthermore, in order to place the particles in a desired isotherm, the injector exit is angled with respect to the plasma centerline. The use of powders manufactured to be near monosized proved the validity of the concept. ${ }^{[7]}$ SPPS can inherently handle powders with a wider size distribution through particle segregation associated with the aerodynamics of the injector. Generally, coating quality is re-

Y.J. Su and K.T. Faber, Department of Materials Science and Engineering, Northwestern University, Evanston, IL 60208; and T.F. Bernecki, Advanced Coatings Technology Group, Northwestern University, Evanston, IL 60201. Contact e-mail: k-faber@northwestern.edu. duced due to the presence of particles with off-design diameters in the mantle of the plasma. The behavior of these particles affects splat formation and, thereby, coating quality and performance.

Ultimately, the selected plasma spray-processing parameters control the dimensions of the hot zone, the temperature and enthalpy distributions, and the particle trajectory in the flame. ${ }^{[8]}$ In turn, these factors determine the in-flight particle temperature and velocity that affect splat formation. The splat geometry and degree of contact with the underlying surface, in turn, affect the coating properties and performance. For example, particles with low temperature and velocity deform less on collision, resulting in increased coating porosity ${ }^{[8]}$ or poor coating adhesion. ${ }^{[9]}$ However, superheated particles can experience a high degree of splashing on impact. The resultant debris can affect defect formation, as well as the final surface roughness. ${ }^{[10]}$ Excessive debris can result in fragmented splats, heavily microcracked microstructures, and lower flexural strength. ${ }^{[10]}$ Thus, it is important to understand the temperature and velocity capabilities of a particular plasma spray system, as well as to understand how to fine-tune these particle properties for enhanced coating performance.

The particle temperature and velocity of internally injected powders have been extensively studied experimentally ${ }^{[1,11,12]}$ and theoretically. ${ }^{[13-15]}$ However, fewer studies exist on the temperature and velocity of externally injected powders. ${ }^{[16-18]}$ The effect of the angled SPPS injector tip on particle properties has never been quantified. In the present work, the influence of particle trajectory on externally injected $7 \mathrm{wt} . \%$ yttria-stabilized zirconia $\left(\mathrm{Y}_{2} \mathrm{O}_{3}-\mathrm{ZrO}_{2}\right.$ or $\left.\mathrm{YSZ}\right)$ and yttrium-aluminum-garnet $\left(\mathrm{Y}_{3} \mathrm{Al}_{5} \mathrm{O}_{12}\right.$ or YAG) powder in SPPS is examined. These particular powders were selected because YSZ/YAG multilayer coatings currently demonstrate potential as thermal barrier coatings with enhanced oxidation resistance. ${ }^{[19]}$ Specifically, this work investigates the effect of four powder injection parameters on the in situ position, velocity, and temperature of the particles for a given set of plasma gun conditions. 


\section{Experimental Methods}

\subsection{SPPS}

SPPS is a modified air plasma spray system with a unique particle injector possessing a narrower injection channel and a beveled injection outlet. ${ }^{[6]}$ This geometry enables greater control over particle temperature and velocity by providing more refined positioning of the particle trajectory in the flame. An external transverse injection Plasma-Technik F-4 gun (Sulzer Metco, Westbury, NY) with a $6 \mathrm{~mm}$ nozzle and an $\mathrm{Ar} / \mathrm{H}_{2}$ gas mixture was used. A constant set of gun conditions was used for each powder as follows: YSZ (power $=35 \mathrm{~kW}$; voltage $=60 \mathrm{~V}$; current $=583 \mathrm{~A}$; the percentage of $\mathrm{H}_{2}$ gas flow $=15$; and total gas flow $=40 \mathrm{slm})$; YAG $($ power $=50 \mathrm{~kW}$; voltage $=67 \mathrm{~V}$; current $=745 \mathrm{~A}$; percentage of $\mathrm{H}_{2}$ gas flow $=29$; and total gas flow $=45$ slm). A Plasma-Technik Twin 10 powder feeder was used. Scanning electron microscope (SEM) images of the starting powders are shown in Fig. 1. The angular YSZ powder (Amperit 825.0, H.C. Stark Inc, Newton, MA) was formed by a fusing-andcrushing process and possesses a mean (Mean \pm SD) particle size of $11.9 \pm 0.2 \mu \mathrm{m}$. The spherical YAG powder, Y3A15 oxide, (Praxair Specialty Ceramics, Woodinville, WA) was formed by combustion spray pyrolysis and has a mean particle size of 23.0 $\pm 0.2 \mu \mathrm{m}$. Particle size distributions for both powders are given in Table 1.

Four spraying parameters directly related to powder injection (i.e., injection angle, injector offset, carrier gas flow, and powder feeder disc speed) were varied at two levels each for the YSZ powder (Table 2). Except for offset, these same parameters were varied at the same levels for the YAG powder. The injection angle and offset are defined from the torch centerline (Fig. 2). The disc speed is given in relative units and describes the rotation rate of the powder feed track. A 16-run and 8-run fullfactorial matrix, plus one center point, was conducted for YSZ and YAG, respectively, to study the effects of these four main factors as well as the two-factor interactions on the particle position, velocity, and temperature in the flame. A full set of replicates was conducted for both materials; however, the data for the YAG replicate was averaged to increase the particle count and to improve the statistics for each set of spraying conditions. Three hundred particles, on average, were analyzed for each run.

\subsection{Particle Diagnostics}

A two-wavelength imaging pyrometer, Particle ThermaViz, (Stratonics, Inc., Laguna Hills, CA [the ability to measure particle size accurately in thermal spray applications is currently being developed]) was used to measure in-flight particle position, surface temperature, and velocity. ${ }^{[20]}$ Surface temperature will be referred to simply as "temperature" for the remainder of the article. The system lies between what Fincke and Neiser ${ }^{[21]}$ have referred to as a single-particle system and an ensemble system. While the temperature and velocity of single particles are measured, due to the large field of view that captures the full width of the flame, the particle properties can be correlated to a position in the flame. Thus, particle temperature, velocity, and spatial distributions can be efficiently determined. The relatively small typical measurement volume requires the optics to traverse the full spray pattern to map velocity and temperature distributions. The temperature is determined from the intensity

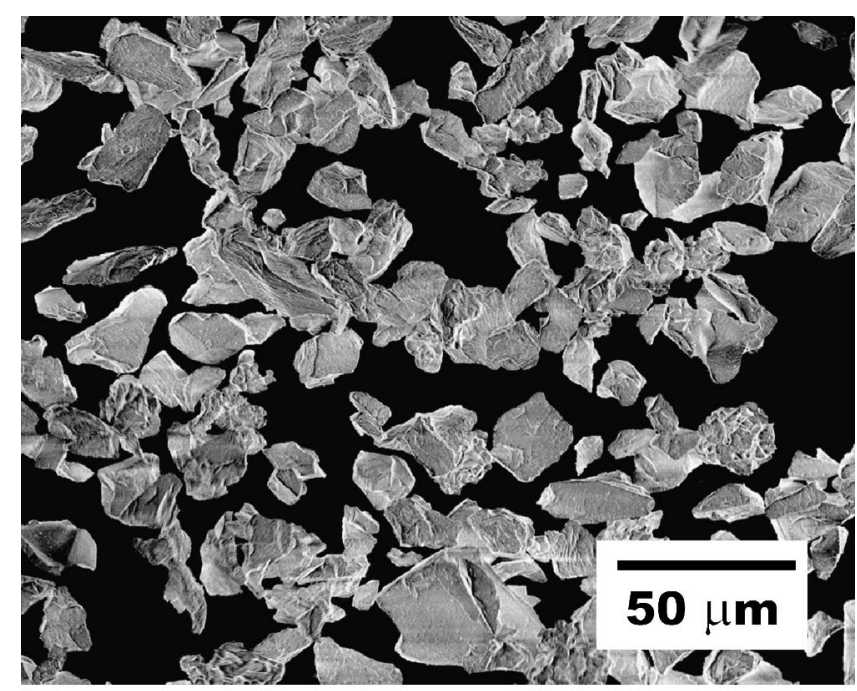

(a)

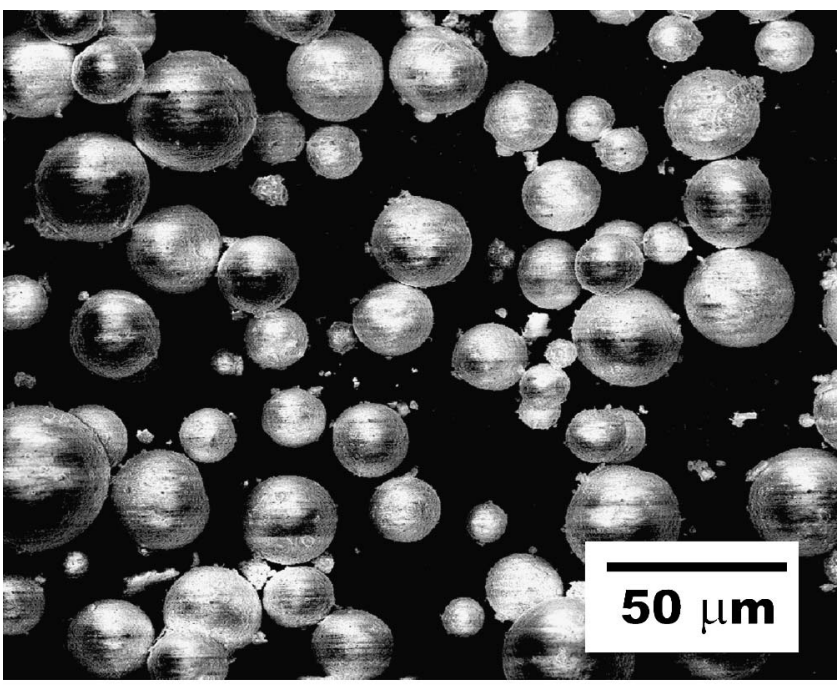

(b)

Fig. 1 SEM images of the starting powders: (a) YSZ powder, mean particle size $12 \mu \mathrm{m}$; and (b) YAG powder, mean particle size $23 \mu \mathrm{m}$

Table 1 Particle Size Distributions for the YSZ and YAG Starting Powders

\begin{tabular}{lcc}
\hline Vol. \% & YSZ & YAG \\
\hline 10 & 17.4 & 32.7 \\
25 & 14.8 & 28.0 \\
50 & 12.1 & 23.4 \\
75 & 9.8 & 19.7 \\
90 & 7.9 & 16.3 \\
\hline
\end{tabular}

ratio of the long and short wavelength images. Using a ratio avoids the need to collect an absolute intensity calibration or the need to know the particle size. ${ }^{[21]}$ The velocity is calculated from the measured particle streak length and the known exposure time.

The camera was positioned perpendicular to the flame at a typical spray distance of $6 \mathrm{~cm}$ from the nozzle exit (Fig. 2). The gun remained stationary as particle measurements were col- 


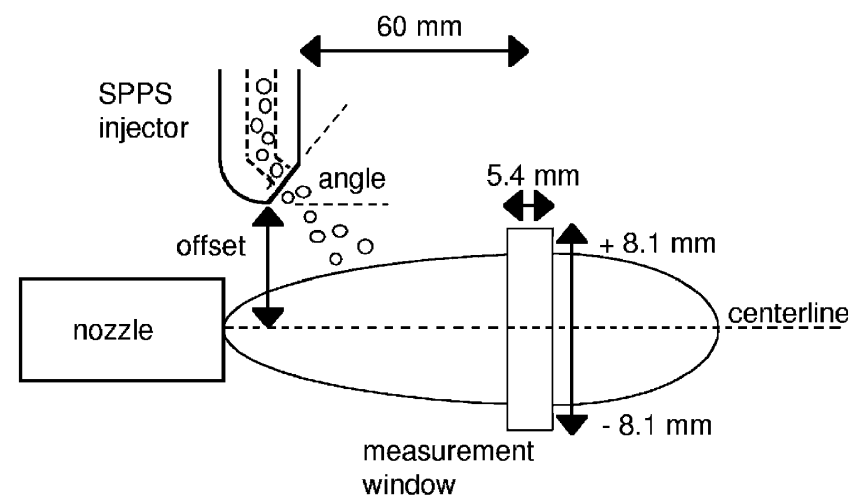

Fig. 2 Schematic drawing of SPPS gun and camera measurement window

Table 2 Factors and Levels Varied in Full-Factorial Experiments

\begin{tabular}{lc}
\hline Parameters & Levels \\
\hline Injector angle, $^{\circ}$ & 30,50 \\
Injector offset (a), mm $_{\text {Carrier gas flow, slm }}$ & 8,11 \\
Disc speed, rpm & 5,7 \\
\end{tabular}

(a) Only varied for YSZ.

lected. At each gun setting, approximately 300 frames were collected with $5 \mu$ s and $4 \mu$ s exposure times, respectively, per frame for YSZ and YAG. The pyrometer was calibrated with a tungsten filament lamp that produces an uncertainty of about $8 \mathrm{~K}$. The temperature and velocity resolution of the pyrometer are approximately $0.4 \%$ and $1.5 \%$, respectively.

Preliminary testing demonstrated that the diagnostic equipment used in this study could not detect alumina particles of less than $10 \mu \mathrm{m}$ in diameter with increasing resolution to $30 \mu \mathrm{m}$. Therefore, the equipment allowed the evaluation of the effect of oversized large particles in the mantle and the modification of processing parameters needed to improve coating quality for a given particle size distribution. As the particle size distribution analysis (Coulter Electronics Multisizer, Beckman Coulter Particle Characterization, Coulter Electronics, Miami, FL) in Table 1 indicates, 75 vol. $\%$ of the YSZ particles have a diameter greater than $9.8 \pm 0.2 \mu \mathrm{m}$. For the YAG powder, 90 vol. $\%$ of the particles are larger than $19.7 \pm 0.2 \mu \mathrm{m}$ in diameter. Thus, the camera detects and measures the majority of the particles in both of the distributions.

\subsection{Coating Property Measurements}

Coating density was obtained using free-standing YSZ coatings. YSZ coatings were initially plasma-sprayed on aluminumcoated steel substrates. The aluminum was etched away using a dilute solution of hydrochloric acid to obtain free-standing coatings. An Archimedes' immersion method based on ASTM C-373 was used to measure the bulk coating density, which accounts for the total porosity (open and closed) in the coating. One sample from each spray condition was evaluated.

Single splats were investigated by modifying the robot scanning program. The gun rastering speed was increased to four times the nominal speed of $350 \mathrm{~mm} / \mathrm{s}$. The drop distance between passes was increased from 3 to $6 \mathrm{~mm}$. A single scan was made across a polished steel substrate to obtain a dusting of isolated splats.

\subsection{Multiple Regression Analysis}

Multiple regression analysis was used to determine the statistically significant main factors and two-factor interactions affecting the particle position, velocity, and temperature. The constructed regression models were used to predict the particle properties for various spraying conditions. Confirmation runs were conducted to check the model's validity within $95 \%$ confidence intervals.

The following statistical terms relevant to the analysis are described below.

1) $t$ ratio is the ratio of the magnitude of a factor's coefficient to the SD of the coefficient, and magnitude indicates the factor's statistical significance on the response;

2) $S_{\text {test }}$ is the sample variance describing the variability in each run;

3) $S_{y . x}$ is the sample variance not explained by the model;

4) DOF is the number of degrees of freedom in the model;

5) $R^{2}$ is the goodness-of-fit parameter describing the percentage of variation in the data explained by the model; and

6) adjusted $R^{2}$ is the goodness-of-fit parameter that accounts for the variability in the test itself.

The following definitions and general guidelines were used in designing the regression models (Multiple Correlation Software, Harold S. Haller Corp., Cleveland, $\mathrm{OH}$ ): (1) factors with $t$ ratios greater than 2.0 were brought into the model, with the magnitude of the $t$ ratio indicating the relative importance of the factor on the measured response; (2) $S_{y . x}$ must be greater than $\mathrm{S}_{\text {test }}$, meaning that the model cannot explain the data better than the equipment can measure it; and (3) the DOF must be greater than three to avoid overfitting. In the regression equation, the magnitude of the coefficient, relative to the intercept point, indicates the variable's significance on the response.

\section{Results}

\subsection{General Trends}

A plot of average particle temperature versus average velocity for all 17 YSZ runs is shown in Fig. 3. The particle temperatures range from approximately 3000 to $3400 \mathrm{~K}$, all of which are greater than the melting temperature of $2975 \mathrm{~K}$. The velocity values range from approximately 175 to $275 \mathrm{~m} / \mathrm{s}$. The radial distance between the torch centerline and each measured particle was determined and is referred to as the particle position. The position values for all the particles in each run was averaged. This quantity is referred to as the average particle position and is labeled in millimeters for selected runs. The positive and negative values represent positions above and below the centerline, respectively. Thus, a position of zero $(\mathrm{mm})$ refers to the centerline of the torch, which, for simplicity, is assumed to be the centerline of the plume. All the particles spanned a spatial distribution from -4 to $3 \mathrm{~mm}$. The absolute value of the SD of the position values ranged from 2 to $3 \mathrm{~mm}$. 


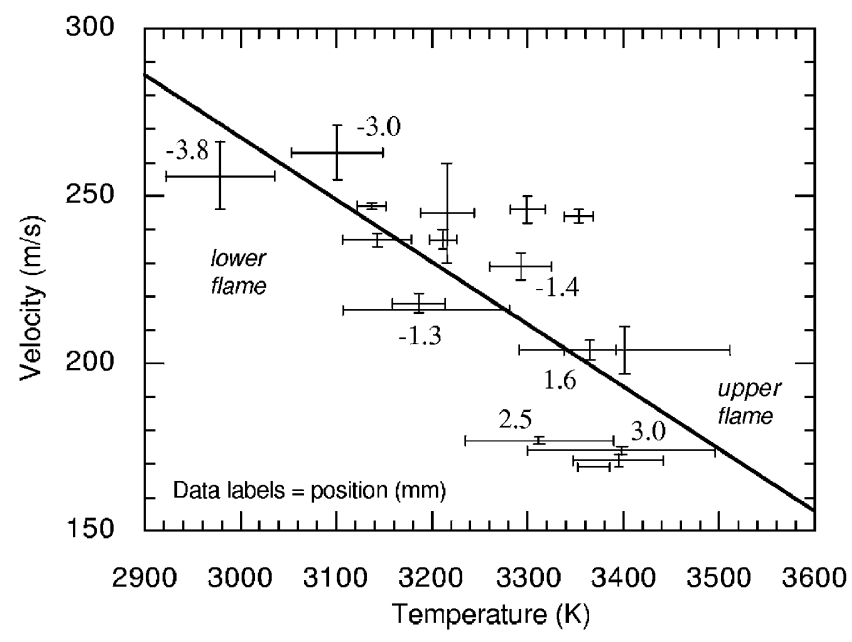

Fig. 3 Plot of average YSZ particle temperature and velocity measurements for all 16 runs. The data labels represent the particle position in the flame, as given by the distance (in $\mathrm{mm}$ ) from the flame centerline (positive $=$ above the centerline; negative $=$ below the centerline)

Two overall trends can be seen in Fig. 3. First, temperature and velocity were inversely related. The particles traveling slower on impact were also hotter. Second, these hotter, slower particles tended to travel in the upper portion of the flame, whereas the cooler, faster particles traveled below the centerline. It is clear that temperature and velocity are both strongly dependent on the particle trajectory and, ultimately, on the particle's location in the flame at the time of impact with the substrate.

Figure 4 shows the average velocity versus average position for the eight YAG runs. The range of position, velocity, and temperature values for the YAG particles is relatively narrow compared to the broad distributions observed with the YSZ particles. The full range of positions from -0 to $3 \mathrm{~mm}-$ are located at or above the torch centerline. Velocity values ranged from 230 to $300 \mathrm{~m} / \mathrm{s}$; the YAG particles in all of the runs traveled at relatively high velocities compared to the YSZ particles. The injection parameters varied in this study and did not affect particle temperature to a significant degree. The average particle temperature was $2955 \mathrm{~K}$ with no statistical difference among the temperatures in the eight runs. The temperatures were all higher than the melting temperature of YAG $(2245 \mathrm{~K})$, however, they also lie at the cooler end of the full range of temperatures observed for YSZ. As observed with YSZ particles, the velocity and position are inversely related (Fig. 4). The faster particles reside near the flame centerline and the slower particles travel in a higher location. The eight runs are largely divided into two rather distinct groups, based on the carrier gas flow level. This will be further discussed in the next few sections in which the regression models are presented.

\subsection{Particle Position}

The regression coefficients and the $t$ ratios of the factors for YSZ particle position are shown in Table 3. Based on their high coefficients and $t$ values, it is clear that the carrier gas flow rate and the injector angle, as well as their interaction, most significantly affected the particle position in the flame. All the other factors that entered the model (i.e., offset, disc speed, and angle-

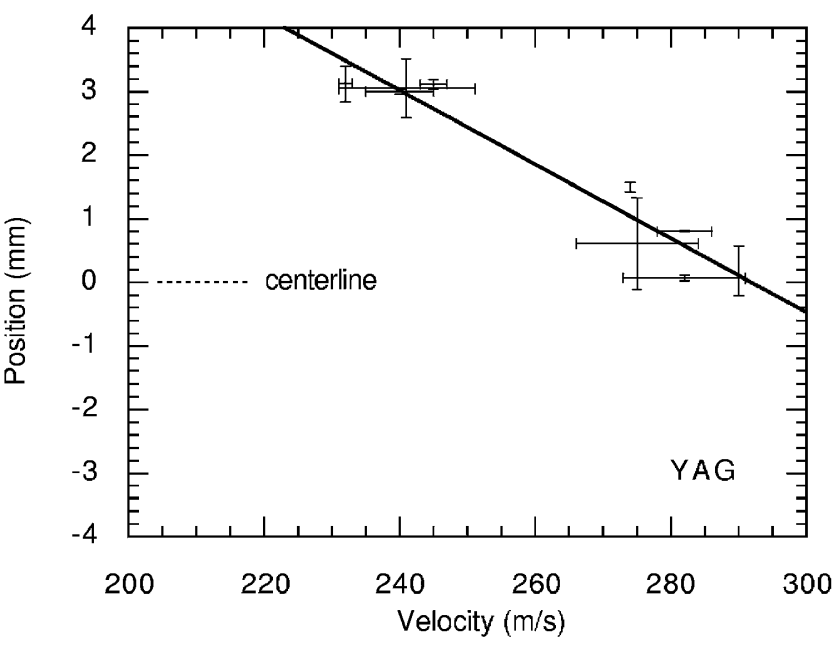

Fig. 4 Plot of average YAG particle position vs velocity for all eight runs

Table 3 Regression Model for Radial Position of YSZ and YAG Particles in Flame

\begin{tabular}{lcr}
\hline Factor & Coefficient & $\boldsymbol{t}$ ratio \\
\hline YSZ position (a) & & \\
Intercept & -0.02 & \\
Carrier gas & -2.14 & -37.30 \\
Angle & 0.97 & 16.82 \\
Disc speed & 0.21 & 3.67 \\
Offset & 0.19 & 3.37 \\
Angle $\times$ carrier & 0.28 & 4.81 \\
Angle $\times$ offset & -0.15 & -2.65 \\
YAG position $(\mathrm{b})$ & & \\
Intercept & 1.74 & -47.12 \\
Carrier gas & -1.3 & 4.35 \\
Angle & 0.12 & 5.95 \\
Angle $\times$ carrier & 0.17 &
\end{tabular}

(a) $S_{y, x}=0.325 ; S_{\text {test }}=0.031 ; \mathrm{DOF}=9 ; R^{2}=98.6 \%$; Adj $R^{2}=99.9 \%$.

(b) $\mathrm{DOF}=4 ; R^{2}=99.8 \%$.

offset interaction) played a less significant role. The high $R^{2}$ value $(98.6 \%)$ and the large number of DOF (9) indicate that the model describes the majority of the data without overfitting. The average variance in the test is relatively low $\left(S_{\text {test }}=0.031 \mathrm{~mm}\right)$ compared to the full range of position values that was measured. Thus, the adjusted $R^{2}$ value is also high at $99.9 \%$. Confirmation runs were conducted at four points in the parameter space to check model validity. The factors and their respective levels are shown in Table 4. The actual experimental values, along with the predicted values, are plotted in Fig. 5. The experimental values fall close to the predicted values, within the $95 \%$ confidence intervals.

The regression model for the YAG particle position is shown in Table 3. The three most significant factors affecting the YSZ particle position (i.e., carrier gas flow, angle, and their interaction) also largely determined the YAG particle position. Although it is a statistically significant variable, the angle has a much lower effect on the YAG particle position compared to that of YSZ particle position, as shown by the order of magnitude of the difference in their $t$ values. This is consistent with the observed two-group division in the data, which is based largely on 


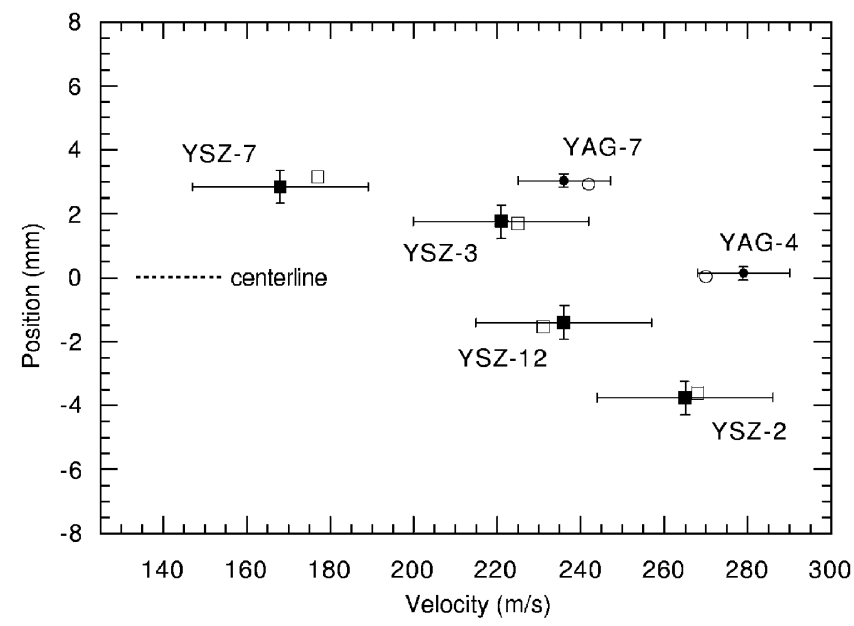

Fig. 5 Plot of particle position vs velocity for YSZ and YAG confirmation runs. ( $\square=$ experimental YSZ; $\square$ = predicted YSZ; $\bigcirc=$ experimental YAG; $=$ predicted YAG values)

Table 4 Confirmation Runs Conducted for YSZ and YAG Models

\begin{tabular}{lcrcc}
\hline Run & Angle, ${ }^{\circ}$ & $\begin{array}{r}\text { Offset, } \\
\text { mm }\end{array}$ & $\begin{array}{c}\text { Carrier } \\
\text { Gas, slm }\end{array}$ & $\begin{array}{r}\text { Disc Speed, } \\
\text { Relative }\end{array}$ \\
\hline YSZ confirmation runs & & & & \\
YSZ-2 & 30 & 8 & 7 & 3 \\
YSZ-3 & 30 & 11 & 3 & 3 \\
YSZ-7 & 50 & 11 & 3 & 3 \\
YSZ-12 & 50 & 8 & 7 & 1 \\
YAG confirmation runs & & & & \\
YAG-4 & 30 & 8 & 7 & 1 \\
YAG-7 & 50 & 8 & 3 & 1 \\
\hline
\end{tabular}

carrier gas flow. The high $R^{2}(99.8 \%)$ and the sufficient DOF (4) indicate that the model explains the experimental data well. Figure 5 shows two confirmation runs that were conducted with their respective predicted values. The model predicts the actual position within the $95 \%$ confidence intervals.

\subsection{Particle Velocity and Temperature}

Table 5 shows the coefficients and $t$ ratios for YSZ particle velocity. Once again, carrier gas flow and injector angle are the two most significant main factors. However, the offset, disc speed, angle-carrier interaction, and angle-disc interaction also affect velocity. The model possesses a high $R^{2}$ value $(93 \%)$ and a large number of DOF (9). Because the variance in the test is relatively low $\left(S_{\text {test }}=8.1 \mathrm{~m} / \mathrm{s}\right)$ compared to the full range of observed velocities, the adjusted $R^{2}$ is also high at $98.0 \%$. The confirmation runs (Fig. 5) indicate that the model predicts velocity values within the $95 \%$ confidence intervals.

The YAG particle velocity model is shown in Table 5. In this case, carrier gas flow and disc speed explained the majority of the data. The model containing only these two main effects possesses a high $R^{2}$ of $97.1 \%$ with reasonable DOF (5). As in the case of position, the carrier gas flow has the largest effect on velocity. The effect of the angle was not found to be statistically
Table 5 Regression Model for Velocity of YSZ and YAG Particles in Flame

\begin{tabular}{lcr}
\hline Factor & Coefficient & $\boldsymbol{t}$ ratio \\
\hline YSZ velocity (a) & 218 & \\
Intercept & 24.2 & 14.47 \\
Carrier gas & -15.9 & -9.53 \\
Angle & 4.16 & 2.49 \\
Disc speed & -3.34 & -2.00 \\
Offset & 5.59 & 3.35 \\
Angle $\times$ carrier & -5.03 & -3.01 \\
Angle $\times$ offset & & \\
YAG velocity (b) & 261 & 12.85 \\
Intercept & 21.4 & 2.03 \\
Carrier gas & 3.38 & \\
Disc speed & & \\
(a) $S_{y, x}=9.44 ; S_{\text {test }}=8.07 ;$ DOF $=9 ; R^{2}=93.0 \% ;$ Adj $R^{2}=98.0 \%$. & \\
(b) DOF $=5 ; R^{2}=97.1 \%$. & & \\
\hline
\end{tabular}

Table 6 Regression Model for Temperature of YSZ Particles in Flame

\begin{tabular}{lcr}
\hline Factor & Coefficient & $\boldsymbol{t}$ ratio \\
\hline YSZ temperature (a) & & \\
Intercept & 3250 & -4.40 \\
Carrier gas & -71.03 & 3.66 \\
Angle & 59.03 & -2.50 \\
Disc speed & -40.28 & \\
(a) $S_{y, x}=91.33 ; S_{\text {test }}=77.67 ; \mathrm{DOF}=12 ; R^{2}=58.2 \% ;$ Adj $R^{2}=82.6 \%$. \\
\hline
\end{tabular}

significant. The experimental and predicted velocity values for the two confirmation runs are shown in Fig. 5. The model predicts the actual velocities within the $95 \%$ confidence intervals.

The coefficients and $t$ ratios for YSZ particle temperature are shown in Table 6 . Since the average variance in each run was relatively high compared to the full range of observed temperatures, the $R^{2}$ value (58\%) for this model is relatively low. However, using a goodness-of-fit parameter the calculation of which accounts for the high test variance, the model predicts most of the data as seen by the adjusted $R^{2}$ of $82.6 \%$. As seen in Fig. 6, the model does predict the experimental confirmation runs quite well. Nonetheless, the $95 \%$ confidence intervals are rather large due to the high variability in the measurements for each run.

\subsection{Effect of Injector Angle}

The effect of the SPPS injector versus a conventional straight injector on the YSZ particle temperature and velocity is shown in Fig. 7. In the three runs shown, the $30^{\circ}$ and $50^{\circ}$ runs were selected from the original full factorial. The other three main factors were held constant at the following levels: radial offset $=$ $11 \mathrm{~mm}$; carrier gas flow $=3 \mathrm{slm}$; and disc speed $=0.3 \mathrm{rpm}$. It is clear that the particles are cooler and travel faster when injected straight into the core of the flame. They obtain higher temperatures and lower velocities as the angle is increased and the injection location is moved further from the plasma core.

\subsection{Coating Microstructure and Density}

Full YSZ coatings were fabricated using the spray parameters from the confirmation runs. Cross-sections of the YSZ 


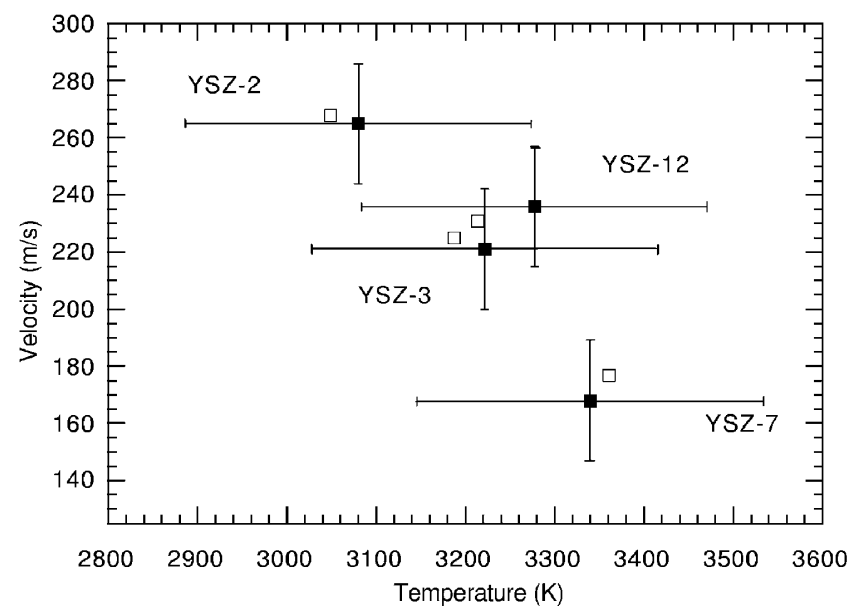

Fig. 6 Plot of temperature versus velocity for YSZ confirmation runs. ( $\square=$ experimental values; $\mathbf{\square}=$ predicted values)

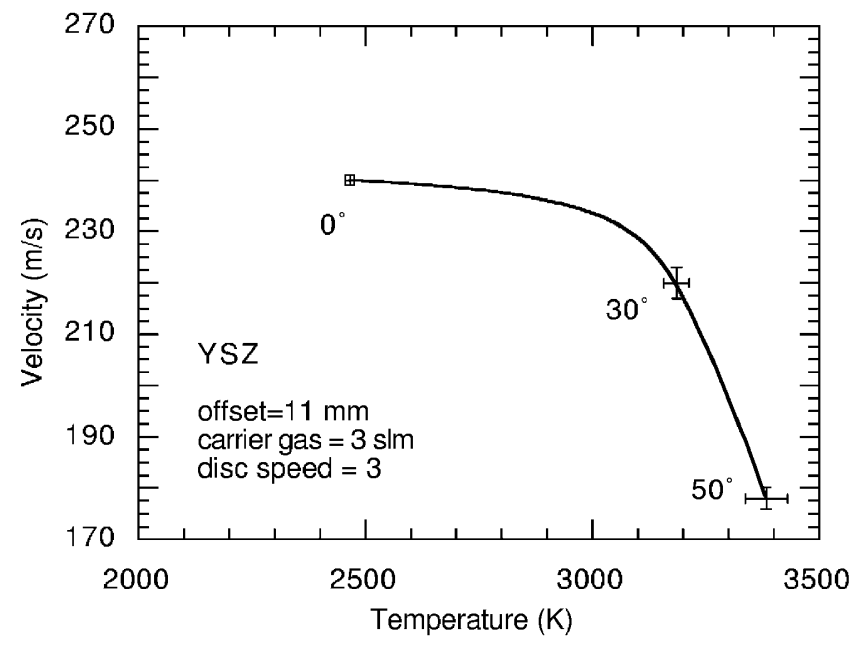

Fig. 7 Plot of temperature versus velocity showing the effect of injector angle on YSZ powder

coatings, as seen in high and low magnification in the SEM, are shown in Fig. 8. Microstructural differences in the coatings are difficult to discern on this scale, and the coatings appear to be somewhat similar. However, density measurements reveal a measurable difference in the percentage of porosity. Plots of coating density versus particle velocity and temperature are given in Fig. 9, with the density given as a percentage of the theoretical bulk density $\left(6.08 \mathrm{~g} / \mathrm{cm}^{3}\right)$. There is a strong correlation among particle position, velocity, and temperature, as coatings formed by slower, hotter particles are more porous than those built up by faster, cooler particles.

\section{Discussion}

\subsection{Temperature and Velocity Relationship}

The temperature and velocity values measured in this study are typical for plasma-sprayed ceramics. Prystay et al. ${ }^{[1]}$ reported similar values for internally injected plasma-sprayed
YSZ. The inverse relationship between YSZ temperature and velocity, and the overall lower temperatures and higher velocities for YAG can be understood in terms of dwell-time. Various researchers have discussed the importance of residence time in the flame on particle temperature. ${ }^{[22]}$ Particle temperature rises due to heat transfer from the plasma flame to the particle surface and interior. Increasing the particle residence time in the hot zone of the flame enhances the heat-transfer process. Assuming a negligible difference in travel distance, the dwell-time for a higher velocity particle will be shorter than that for a lower velocity particle. From this standpoint, the inverse relationship observed between the YSZ particle temperature and velocity is expected. The lower overall particle temperatures observed for the significantly larger YAG particles are likely due to their higher velocities and insufficient dwell-time in the flame. ${ }^{[23]}$ Particle size also plays a role in heat transfer and is further discussed below.

\subsection{Temperature/Position and Velocity/Position Relationships}

The direct relationship between temperature and position and the indirect relationship between velocity and position is likely due to aerodynamic particle-sizing effects. The cooler, faster YSZ particles that travel in the lower part of the flame already have passed through the plasma centerline. In this process, the smallest particles in the distribution are not entrained into the lower flame. This can be attributed either to vaporization in the core $^{[12]}$ (the hottest, fastest portion of the plume) or the lack of momentum required to further penetrate the flame..$^{[11,13,16]}$ It is then feasible that the YSZ particles in the lower flame are primarily larger particles. In the upper part of the flame, presumably the majority of the particles in the distribution are present since the particles do not experience conditions sufficient for vaporization. Cetegen and $\mathrm{Yu}^{[16]}$ have observed similar size separation in the flame while plasma-spraying YSZ. They found that larger particles have a greater tendency to penetrate further into the flame, whereas smaller particles are more easily carried away by the momentum of the plasma jet and remain in the upper portion of the flame. Fincke et al. ${ }^{[11,13]}$ also observed a spatial size distribution of internally injected Ni-Al particles in which larger particles were detected farther from the centerline. This concept of aerodynamic size segregation leads to the following question: why are the smaller particles in the upper flame hotter and slower?

Heat transfer occurs by convection between the flame and the particle surface and by conduction between the particle interior and its surface. A temperature gradient exists over the distance $L$, equal to the particle's volume divided by its surface area. For a spherical particle, $L=R / 3$, where $R$ is the radius. The ratio of the conduction resistance to the convection resistance defines the Biot number, $\mathrm{Bi}=h L / k$, where $h$ is the heat transfer coefficient and $k$ is the thermal conductivity of the solid particle. ${ }^{[24]}$ Particles with a large $\mathrm{Bi}$ can display significant temperature gradients within the particle. ${ }^{[21]}$ Because $h$ and $k$ will not change with particle size, there will be a factor of 4 difference in the Biot number between the largest ( $20 \mu \mathrm{m}$ for the YSZ) and smallest ( 5 $\mu \mathrm{m}$ for the YSZ) particles of a given material. In other words, the interior of the largest particle is four times more resistant to heating than that of the smallest particles. Michin et al. ${ }^{[25]}$ observed 


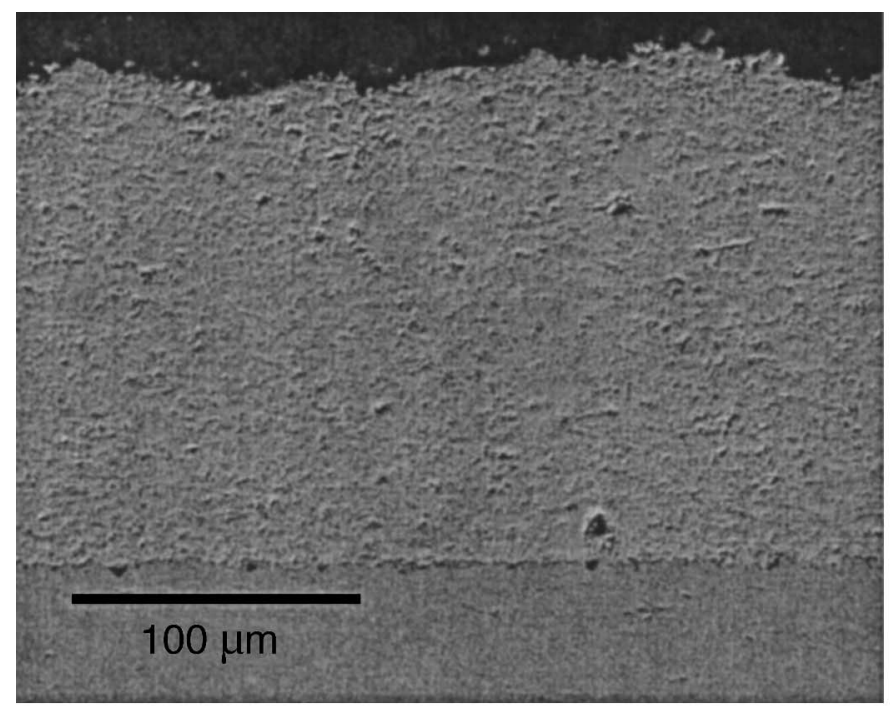

(a) YSZ $87.5 \%$ dense

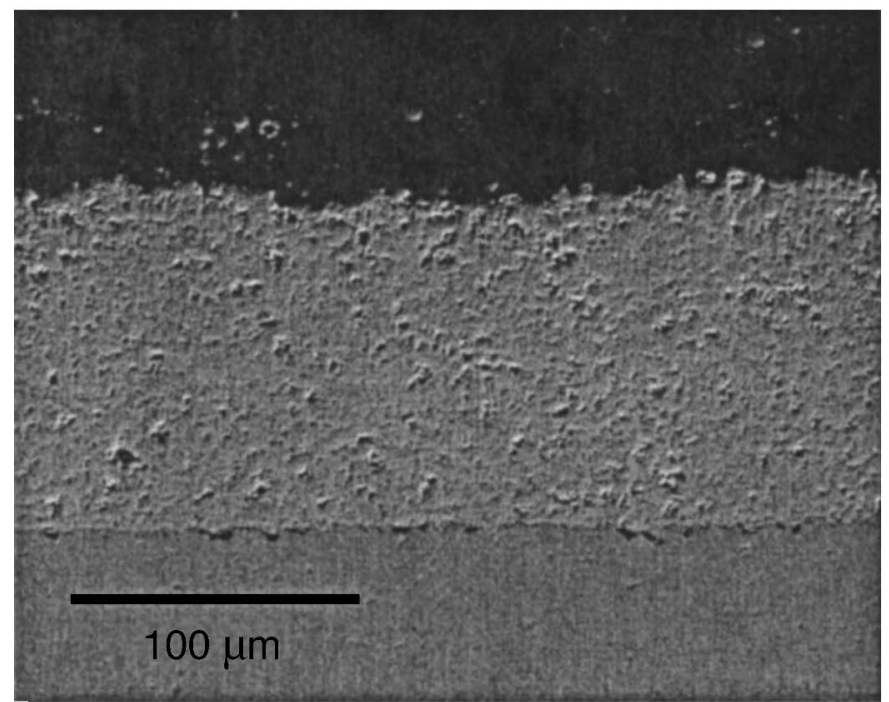

(c) YSZ-12 $89.8 \%$ dense

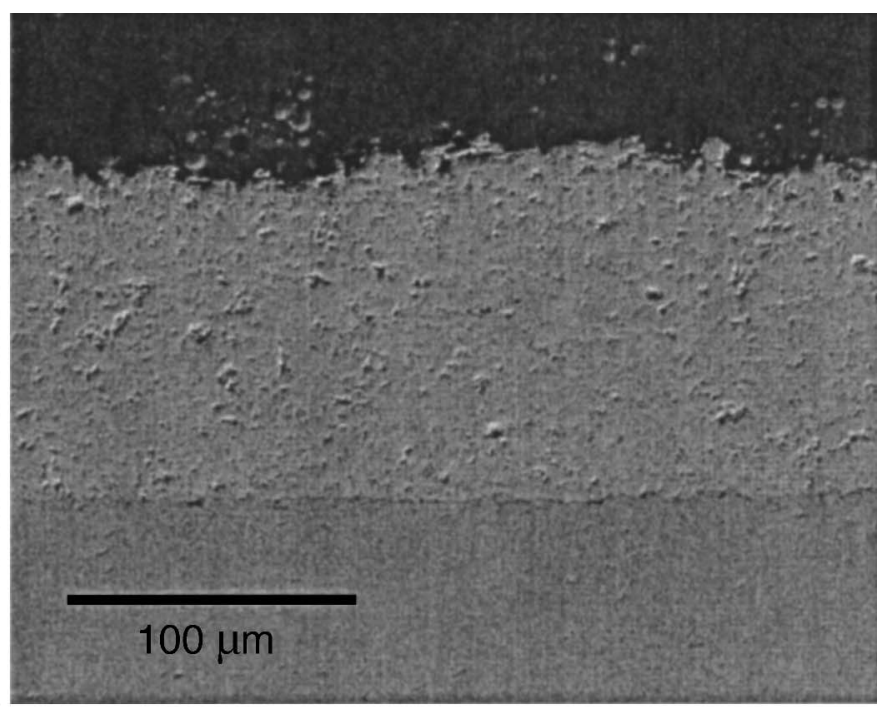

(b) YSZ-3 $89.4 \%$ dense

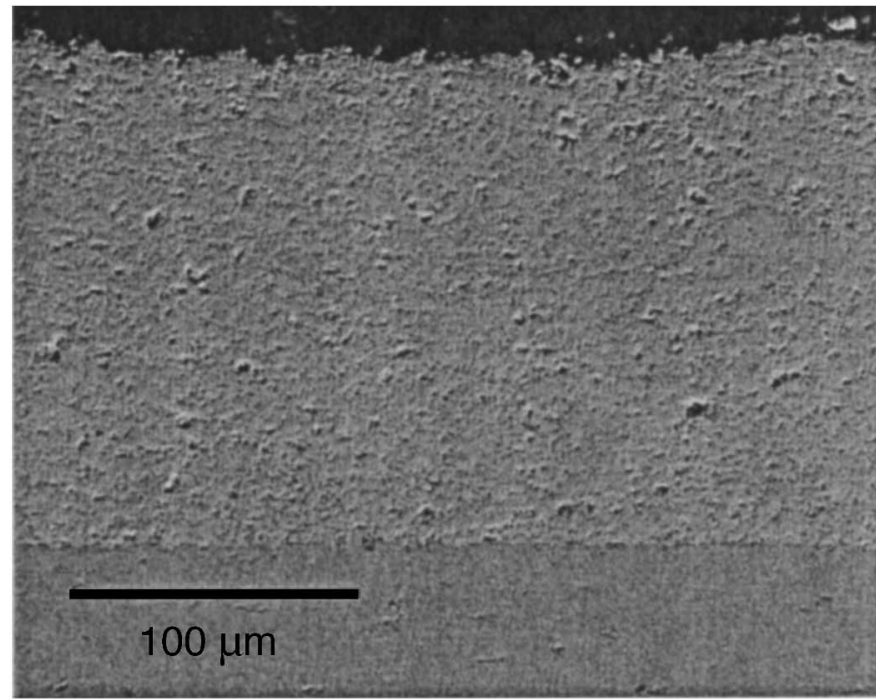

(d) YSZ-2 $90.8 \%$ dense

Fig. 8 Cross-sectional SEM images of coatings formed using the confirmation run spray settings. The particle temperature decreases, particle velocity increases, and coating density increases from (a) to (d).

a $100 \mathrm{~K}$ difference in the surface temperature of alumina particles with a factor of 2.5 difference in the Biot number. According to Zaat ${ }^{[8]}$ heat transfer to the particles is predominately governed by conduction through the solid particle. This would further enhance the resistance of larger particles to interior heating. Thus, if mainly larger particles reside in the lower portion of the flame, it is not surprising that they have a lower average temperature than the dominating smaller particles in the upper portion of the flame.

The larger particles found in the lower portion of the flame travel at higher velocities due to velocity distributions within the flame itself. The highest flame velocities are present in the core. ${ }^{[12,22]}$ As the larger particles penetrate the core of the flame, they are accelerated by the increased momentum of the flame and, thus, travel with a higher average velocity. In addition, larger particles tend to retain more of their momentum as they travel through the flame. This can result in larger particles possessing higher velocities farther downstream. ${ }^{[14]}$

\subsection{Parameter Main Effects and Interactions}

The carrier gas flow rate, injector angle, and disc speed were the most significant factors affecting all three measured responses (i.e., position, velocity, and temperature). Increasing carrier gas flow, decreasing the angle, and increasing disc speed result in a lower flame position and lower temperature. And, except for disc speed, these same trends result in a higher velocity. The carrier gas flow determines the initial powder injection 


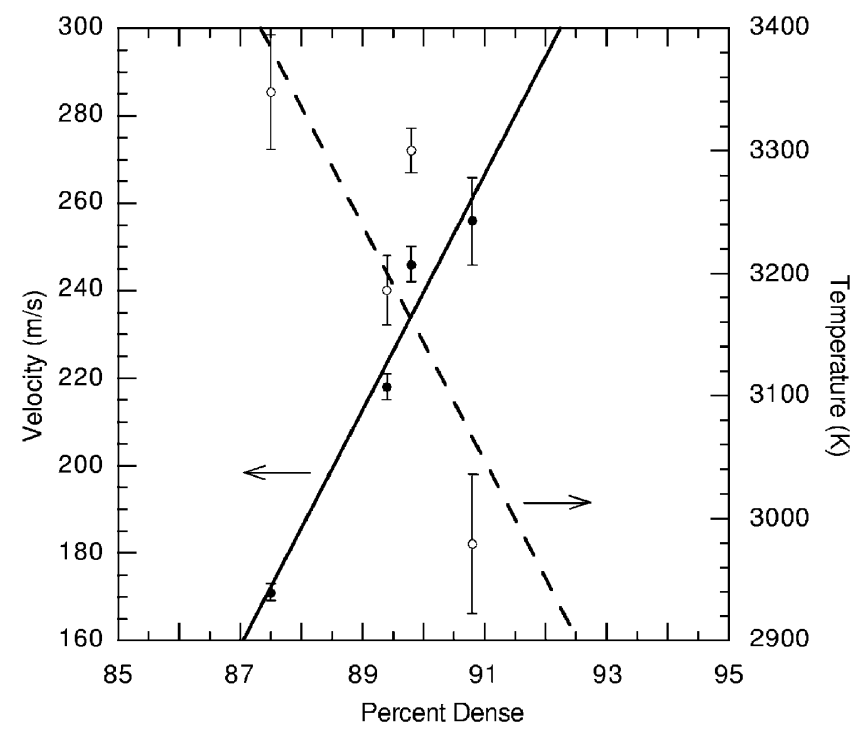

Fig. 9 Particle velocity and temperature vs percent density for YSZ confirmation runs

velocity and serves to cool the flame. With a higher gas flow, particles are injected faster and are able to penetrate farther into the flame, potentially passing through the core, as well as travel with a faster average velocity. Also, a cooler flame has less heat available to transfer to the particles, producing lower particle temperatures. Furthermore, the carrier gas flow rate and disc speed control the powder feed rate. Increasing both factors results in a higher feed rate and, thus, higher particle loading. The more powder present in the flame, the less heat each individual particle receives, and the lower the average particle temperature.

The injector angle mainly affects the initial injection position of the particles and their subsequent trajectory in the flame. A higher angle allows the powder to be gradually entrained into the flame, enabling particles to reside in the upper periphery of the flame. Lowering the angle and injecting the powder directly into the core of the flame result in greater difficulty for the smaller particles in the distribution to become entrained in the flame. This leads to the size-segregation effects discussed earlier. Using a steeper angle enables the smaller particles to be sprayed more effectively as their trajectory bypasses the core. Because the YAG powder does not contain small enough particles that are more difficult to entrain in the core of the plasma, the YAG particles were less sensitive to the change in injector angle than are the YSZ particles. Nonetheless, the position regression models indicate that both powders travel higher in the flame when a steeper angle is used.

Beyond the physical interpretations, plots of particle temperature versus velocity, such as that shown in Fig. 7, provide a useful guide for optimizing the angle required to sufficiently melt particles under a given set of spraying conditions. By altering the base set of spraying conditions, a particle temperaturevelocity field map can be generated for a more complete understanding of the system capabilities.

It is not surprising that the angle was found to interact with the carrier gas flow and the radial offset (Tables 3 and 5). Due to the injector geometry and the position with respect to the flame, various combinations of angle/offset or angle/carrier gas flow can result in an identical particle injection location. For example, based on trigonometry, powder is injected at a horizontal distance of $6.4 \mathrm{~mm}$ from the nozzle exit while using a $30^{\circ}$ angle $/ 11$ $\mathrm{mm}$ offset, as well as a $40^{\circ}$ angle $/ 8 \mathrm{~mm}$ offset (Fig. 2). The relationship between angle and carrier gas flow can be thought of in a similar manner.

\subsection{Coating Density and Splat Geometry}

The effect of particle temperature and velocity on coating density can be understood by looking at single splats. Figure 10 reveals typical splat morphologies for the four YSZ confirmation runs. In the case of YSZ, because all the particle temperatures are higher than the melting temperature and there is an insignificant fraction of unmelted particles, we can speculate that the particle velocity dominates the spreading behavior on impact. All of the splats appear to be well melted and spread to varying degrees. After the initial impact, the splat edges of the slower particles retracted, as indicated by the raised perimeter that is visible in Fig. 10(a). This indicates that the slower particles were afforded a longer solidification time and a slower quenching rate. This is likely due to the presence of porosity beneath the splats, which reduces the rate of heat transfer from the particle to the substrate or previously applied splat. ${ }^{[26]}$ The presence of more intrasplat porosity on impact of the slower particles is evident in Fig. 10(a). This is consistent with the density versus velocity trends presented in Fig. 9.

As the impact velocity increases, the splats exhibit a greater degree of spreading and improved contact with the substrate. They have a greater tendency to form "fingers" and to produce string-like debris on impact, compared to their slower counterparts (Fig. 10b). As the velocity is raised further, the splats exhibit more of an explosive pattern, the fingers begin to break off, and debris of various shapes randomly scatters (Fig. 10c). However, at extremely high velocities the debris falls back on the splat from which it originated (Fig. 10d).

Although the melting temperature of YAG is less than the observed particle temperatures, a large fraction of unmelted or partially melted particles was observed in the single-splat study (Fig. 11a). This is likely due to the large particle size and high Biot number, as discussed previously. However, there is still a distinct difference between the splats of the two confirmation runs due to the variation in velocity. Consistent with the YSZ observations, the faster particles exhibited increasing flattening and finger formation (Fig. 11b and c). Based on the YSZ trends, it is expected that the slower moving particles shown in Fig. 11(b) would form a more porous coating.

\section{Conclusions}

YSZ and YAG powders sprayed by SPPS were investigated using a two-wavelength imaging pyrometer. Particle position, velocity, and temperature were measured in flight at a typical spray distance. Carrier gas flow, injector angle, and powder feeder disc speed had a significant effect on all three properties. A lower carrier gas flow, a higher angle, and a lower powder feeder disc speed resulted in a lower particle temperature and a higher velocity. Due to aerodynamic particle sizing within the flame, particle temperature and velocity were a function of the 


\author{
Decreasing $\mathbf{T}$ More spreading and fingering \\ Increasing $\mathrm{V}$ and More debris \\ Increasing $\rho$
}

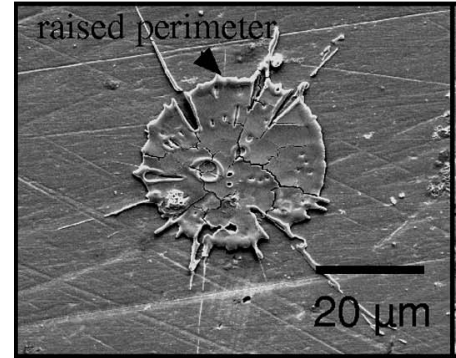

(a) YSZ-7

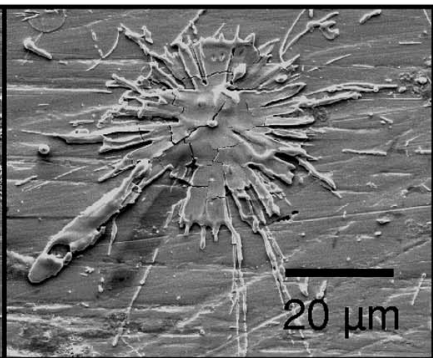

(b) YSZ-3

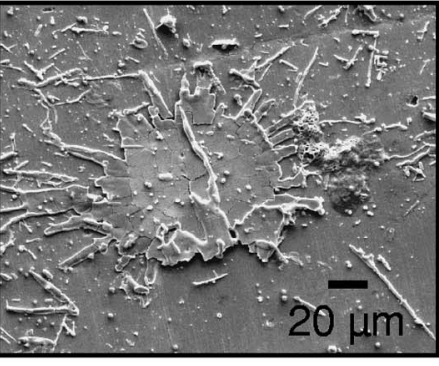

(c) YSZ-12

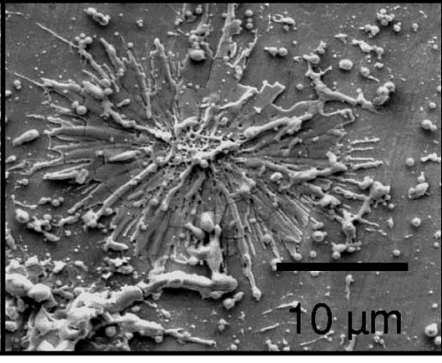

(d) YSZ-2

Fig. 10 Splat morphology under the YSZ confirmation runs

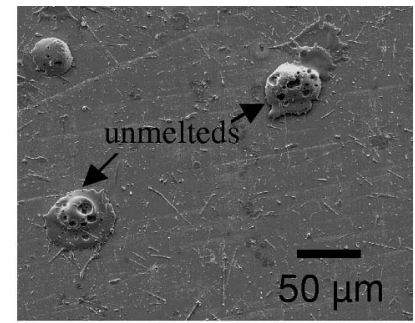

(a)

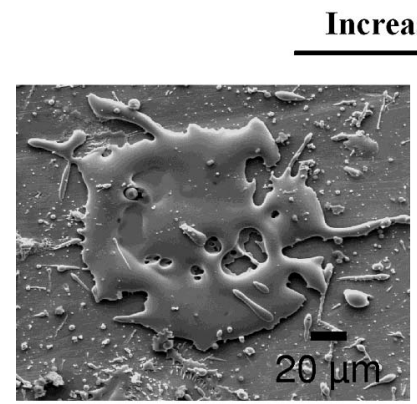

(b) YAG-7

Fig. 11 YAG splat morphology showing (a) unmelted or partially melted particles, (b) low-velocity confirmation run, and (c) highvelocity confirmation run

particle trajectory and position in the flame. Larger particles traveled in the lower portion of the flame with a higher velocity and possessed a lower temperature due to less residence time in the flame and a higher Biot number. Smaller particles travel in the upper portion of the plume with a lower velocity and reach higher temperatures. The use of a beveled injection tip does in fact permit more effective spraying of smaller particles. The differences in temperature and velocity are reflected in the coating density and splat formation. Lower density coatings are formed by splats of slower, hotter particles that possess a larger fraction of intrasplat and intersplat porosity.

\section{Acknowledgments}

The authors would like to thank Rick Marzec of the Advanced Coatings Technology Group at Northwestern University for general assistance in the thermal spray laboratory, Ronald Parker of Stratonics Inc. for technical assistance with the pyrometer hardware and software, and John Montgomery for carefully reviewing the manuscript. This work was supported by the U.S. Department of Energy, Federal Energy Technology Center, Cooperative Agreement No. DE-FC21-92MC29061, under subcontract No. 96-01-SR047.

\section{References}

1. M. Prystay, P. Gougeon, and C. Moreau: "Correlation between Particle Temperature and Velocity and the Structure of Plasma Sprayed Zirconia Coatings," in Thermal Spray: Practical Solution for Engineering Problems: Proceedings of the 9th National Thermal Spray Conference, 7-11 October 1996.

2. L.C. Erickson, T. Troczynski, H.M. Hawthorne, H. Tai, and D. Ross: "Alumina Coatings by Plasma Spraying of Monosize Sapphire Particles," J. Thermal Spray Technol., 199, 8(3), pp. 421-26.

3. M. Vardelle, A. Vardelle, P. Fauchais, and C. Moreau: "Pyrometer System for Monitoring the Particle Impact on a Substrate During a Plasma Process," Meas. Sci. Technol., 1994, 5, pp. 205-12.

4. B. Champagne and S. Dallaire: "Particle Injection in Plasma Spraying," in Thermal Spray: Advances in Coatings Technology, D.L. Houck, ed., ASM International, Orlando, FL, 1988, pp. 25-32.

5. A.R.D. Arellano-Lopez and K.T. Faber: "Microstructural Evolution of Small-Particle Plasma Spray," J. Am. Ceram. Soc., 1999, 82(8), pp. 2204-08.

6. T.F. Bernecki and D.R. Marron: Small Particle Plasma Spray Apparatus, Methods, and Coated Article, U.S. Patent 5,744,777, April 28, 1998; and U.S. Patent 5,858,470, Jan. 12, 1999.

7. T. F. Bernecki: Northwestern University, unpublished paper, 1995.

8. J.H. Zaat: "A Quarter of a Century of Plasma Spraying," Ann. Rev. Mater. Sci., 1983, 13, pp. 9-42.

9. A. Vardelle, M. Moreau, and P. Fauchais: "The Dynamics of Deposit Formation in Thermal Spray Processes," MRS Bull., 2000, 7, pp. 32-37.

10. R. Trice and K.T. Faber: "The Role of Lamellae Morphology on the Microstructural Development and Mechanical Properties of SmallParticle Plasma-Sprayed Alumina," J. Am. Ceram. Soc., 2000, 83(4), pp. 889-96.

11. J.R. Fincke, W.D. Swank, and C.L. Jeffery: "Simultaneous Measurement of Particle Size, Velocity, and Temperature in Thermal Plasmas," IEEE Trans. Plasma Sci., 1990, 18(6), pp. 948-57.

12. E. Pfender: "Fundamental Studies Associated with the Plasma Spray 
Process," in Thermal Spray: Advances in Coatings Technology, D.L. Houck, ed., ASM International, Orlando, FL, 1987, pp. 1-10.

13. J.R. Fincke, W.D. Swank, C.L. Jeffery, and C.A. Mancuso: "Simultaneous Measurement of Particle Size, Velocity, and Temperature," Meas. Sci. Technol., 1993, 4, pp. 559-65.

14. S.V. Joshi and R. Sivakumar: "Prediction of In-flight Particle Parameters During Plasma Spraying of Ceramic Powders," Mater. Sci. Technol., 1992, 8(6), pp. 481-88.

15. D.K. Das and R. Sivakumar. "Modelling of the Temperature and the Velocity of Ceramic Powder Particles in a Plasma Flame: II. Zirconia," Acta Metall. Mater., 1990, 38(11), pp. 2193-98.

16. B.M. Cetegen and W. Yu: "In-Situ Particle Temperature, Velocity, and Size Measurements in DC Arc Plasma Thermal Sprays," J. Thermal Spray Technol., 1999, 8(1), pp. 57-67.

17. M. Vardelle, A. Vardelle, A.C. Leger, P. Fauchais, et al.: "Influence of Particle Parameters at Impact on Splat Formation and Solidification in Plasma Spraying Processes," J. Thermal Spray Technol., 1994, 4(1), pp. 50-58.

18. S. Fantassi, M. Vardelle, A. Vardelle, and P. Fauchais: "Influence of the Velocity of Plasma Sprayed Particles on the Splat Formation," Thermal Spray Coatings: Research, Design, and Applications: Proceedings of the 5th National Thermal Spray Conference, 7-11 June 1993.

19. Y.J. Su and K.T. Faber: Northwestern University, unpublished paper, 1999.

20. J.E. Craig, R.A. Parker, F.S. Biancaniello, S.D. Ridder, and S.P. Mates: "Particle Temperature Measurements by Spectroscopic and Two-
Wavelength Streak Imaging," in Thermal Spray: Research, Design and Applicators, C.C. Berndt and T.T. Bernecki, ed., ASM International, Materials Park, OH, 2000, pp. 51-56.

21. J.R. Fincke and R.A. Neiser: "Advanced Diagnostics and Modeling of Spray Processs," MRS Bull., 2000, 7, pp. 26-31.

22. P. Boch, P. Fauchais, D. Lombard, B. Rogeaux, and M. Vardell: "Plasma-Sprayed Zirconia Coatings," in Science and Technology of Zirconia II, N. Claussen, M. Ruhle, and A. H. Heuer, ed., 1984, pp. 488502

23. J.E. Craig, R.A. Parker, D.Y. Lee, F. Biancaniello, and S. Ridder: "A Two-wavelength Imaging Pyrometer for Measuring Particle Temperature, Velocity, and Size in Thermal Spray Processes," in Proc. Int. Sym. on Advanced Sensors for Metals Processing, B.W. Brusey, ed., Canadian Institute of Mining, Metallurgy, and Petroleum, Montreal, Quebec, 1999, pp. 369-80.

24. D.R. Gaskell: An Introduction to Transport Phenomena in Materials Engineering, New York, Macmillian Publishing Company, 1992, p. 368.

25. J. Michin, M. Vardelle, J. Lesinksi, and P. Fauchais: "Two-Colour Pyrometer for the Statistical Measurement of the Surface Temperature of Particles Under Thermal Plasma Conditions," J. Physics E. Sci. Instrum., 1987, 20, pp. 620-25.

26. C. Moreau and P. Gougeon: "Influence of Substrate Preparation on the Flattening and Cooling of Plasma-Sprayed Particles," J. Thermal Spray Technol., 1995, 4(1), pp. 25-33. 